\title{
Enrolment in an Asthma Management Program during Pregnancy and Adherence with Inhaled Corticosteroids: The 'Management of Asthma during Pregnancy' Program
}

\author{
Camilla Boslev Baarnes $^{\mathrm{a}}$ Anne Vejen Hansen ${ }^{\mathrm{a}}$ Charlotte Suppli Ulrik ${ }^{\mathrm{a}} \mathrm{b}$ \\ ${ }^{a}$ Department of Pulmonary Medicine, Hvidovre Hospital, Hvidovre, and ${ }^{b}$ Institute of Clinical Medicine, University of \\ Copenhagen, Copenhagen, Denmark
}

\section{Key Words}

Asthma $\cdot$ Pregnancy $\cdot$ Adherence $\cdot$ Controller medication .

Inhaled corticosteroids

\begin{abstract}
Background: Poor adherence with inhaled corticosteroids (ICS) is a major problem in asthma and according to previous studies not least during pregnancy. Objective: Our aim was to assess if enrolment in an asthma management program, and by that close monitoring, can improve self-reported and documented adherence with ICS in pregnant women with asthma. Methods: Pregnant women with doctor-diagnosed asthma, currently being prescribed ICS, referred during a 12-month period to the outpatient respiratory clinic, were consecutively included in the study. They had follow-up visits every 4 weeks during pregnancy. Asthma control was assessed according to GINA guidelines. Self-reported adherence was compared to documented adherence, defined as medical possession rate (MPR), calculated on the basis of filled prescriptions (data from each individuals' medication profile at www.fmk-online.dk). Results: A total of 130 women fulfilled the inclusion criteria, but at the initial visit, 16 women reported no current use of ICS, and the analyses are therefore based on 114 patients. Self-reported adherence to
\end{abstract}

ICS was significantly higher during pregnancy than before pregnancy ( 73 and $52 \%$, respectively, reporting good adherence; $p<0.001)$. The actual adherence, i.e. MPR, was also higher during pregnancy than before (46vs. $28 \%, p<0.0001$ ). In keeping with this, an overall improvement was also observed in asthma control. Of the women with a low pre-pregnancy MPR, $71 \%$ had moderate or good adherence (MPR) during pregnancy. Self-reported adherence was significantly correlated with MPR during pregnancy $(p=0.004)$ but not before pregnancy $(p=0.46)$. At the 3 -month postpartum visit, adherence was close to the pre-pregnancy level. Conclusion: Enrolment in an asthma management program during pregnancy seems to improve adherence with controller medication, but self-reported adherence is not a valid measure for actual adherence in patients with asthma.

(c) 2016 S. Karger AG, Basel

\section{Introduction}

Adherence with inhaled corticosteroids (ICS) is probably the most challenging aspect of asthma management for health care professionals [1]. Despite the safety and efficacy of ICS, adherence remains low, ranging from 20 $73 \%$ [2], and many factors contribute to the individual

\section{KARGER}

E-Mail karger@karger.com

www.karger.com/res
C 2016 S. Karger AG, Basel

0025-7931/16/0921-0009\$39.50/0
Prof. Charlotte Suppli Ulrik, MD, DMS

Department of Pulmonary Medicine

Hvidovre Hospital

DK-2650 Hvidovre (Denmark)

E-Mail csulrik@dadlnet.dk 
patient's willingness to adhere to controller therapy [36]. Several interventions have been investigated aiming at improving ICS adherence [1]. So far, the best results in non-pregnant adults with asthma come from combining two or more interventions, addressing different aspects of poor adherence $[7,8]$.

Asthma is one of the most common chronic diseases among pregnant women with a prevalence of up to $10 \%$ [9]. Previous studies have shown that approximately one third of the women with asthma will experience a worsening of their disease during pregnancy, whereas another third report an improvement in symptoms [10], which points to the importance of frequent re-assessment of asthma control and medication requirements.

Uncontrolled asthma during pregnancy is associated with adverse outcomes for both mother and foetus, including an increased risk of pre-eclampsia, foetal growth retardation, preterm delivery and caesarean delivery [11, 12]. Unfortunately, many women with asthma discontinue or decrease their use of ICS when learning that they are pregnant [13], most likely due to concerns about risks for their unborn child. Most of the women do so without consulting a physician, even though a large number of them claim willingness to continue ICS, provided that they are advised to do so by health care professionals [13]. However, not all physicians are aware of the safety of ICS during pregnancy, as Lim et al. [14] have previously reported that one fourth of the interviewed physicians would either stop or decrease the dose of ICS when a patient becomes pregnant, despite well-controlled asthma.

Current guidelines aim to achieve optimal control of asthma, for the wellbeing of mother and foetus. Control is believed to be gained by assessment and monitoring, elimination of risk factors, patient education and a stepwise approach to medication [15]. Studies have also shown that use of ICS during pregnancy is not associated with negative pregnancy outcomes [16].

The aim of the present prospective study was to investigate the effect of close monitoring, including regular follow-up visits, during pregnancy on self-reported and documented adherence with ICS in pregnant women with asthma.

\section{Patients and Methods}

\section{Patients}

The 'Management of Asthma during Pregnancy' (MAP) program was initiated in 2007, and since then, all pregnant women referred to Hvidovre Hospital (7.000 per year) have, in a welcome letter from the Department of Gynaecology and Obstetrics, been offered participation in the study. Subjects fulfilling the following criteria were included: (1) doctor-diagnosed asthma (ICD-10 code DJ45; defined according to GINA-guidelines [17]); (2) prescribed as needed bronchodilator therapy (Step 1 therapy [17]), and (3) first visit to the outpatient clinic at the Department of Pulmonary Medicine within the first 18 weeks of pregnancy.

Patients were consecutively included in the present study if they also fulfilled the following criteria: (1) visit to the outpatient clinic at the Department of Pulmonary Medicine within the last 4 weeks of pregnancy; (2) reported currently being prescribed ICS at the time of the first visit at the outpatient clinic, and (3) first visit at the outpatient clinic in 2012 (January to December).

\section{Methods}

All pregnant women who accepted the invitation to participate in the study (via e-mail to astmaoggraviditet@ regionh.dk) were offered an appointment at the outpatient clinic, Department of Pulmonary Medicine, within 2 weeks. Following the initial appointment, follow-up visits were scheduled approximately every 4 weeks during pregnancy, and 3 months after giving birth.

Case history was taken, including duration of asthma, treatment, and smoking habits. At the first visit to the outpatient clinic, all participants were provided with general information about asthma treatment, with special emphasis on importance of adherence with controller medication, and written information about asthma and pregnancy.

At every visit data were obtained on day- and night-time symptoms, self-reported adherence, use of rescue medication, assessment of asthma control (according to GINA-guidelines [17]), spirometry, exhaled nitric oxide (FeNO) and body weight. All patients were seen by the same physician (C.S.U) at all visits, and the importance of adherence with controller medication was discussed with the patients at all visits (after their grading of level of adherence).

\section{Spirometry}

Spirometry was performed using the Easy One Ultrasonic spirometer (NDD; Zurich, Switzerland), according to the American Thoracic Society (ATS)/European Respiratory Society recommendation [18], and predicted values for $\mathrm{FEV}_{1}$ and FVC were calculated according to reference equations [19].

\section{Exhaled Nitric Oxide}

FeNO was measured using the nitric oxide analyzer (NIOX; Aerocrine, Solna, Sweden), according to the ATS-guidelines [20]. Guided with the help of a biofeedback monitor, patients exhaled from total lung capacity to residual volume at an expiratory flow rate of $50 \mathrm{ml} / \mathrm{s}$, and against a target resistance of $4-5 \mathrm{~cm}$ water. FeNO was determined as the average of two measurements of the plateau of the FeNO curve.

\section{Adherence to ICS}

At the initial visit, the women were asked to grade their adherence with controller medication during the 9-month pre-pregnancy period, i.e. their usual level of adherence, as good, moderate or low. Likewise, they were asked to grade their adherence at each visit, based on the level of adherence to the prescribed daily dose of controller medication since their last visit, including the 3-month postpartum visit.
Baarnes/Hansen/Ulrik 
Actual adherence to ICS was calculated as medical possession rate (MPR), as total number of days supplied with medicine/ number of days of observation $\times 100$ [21]. The index date was the first day of the last menstrual bleeding, calculated as 270 days before the delivery date. The length of observation was 270 days before the index date (pre-pregnancy values) and the 270 days between the index date and delivery (pregnancy values). Number of days supplied was found by obtaining prescription fill records from www.fmk-online.dk (based on each persons' unique number from the Danish Central Persons Register) and the ICS prescription from the medical records, and dividing the canister size with the number of puffs prescribed per day. Any medication in surplus after day 270 post-conception or filled earlier than 270 days pre-conception was subtracted in order not to overestimate the adherence. Likewise, MPR was calculated for the 3-month postpartum visit. For MPR adherence, the following cut off values was used: non-adherence $(0 \%)$, poor adherence $(<40 \%)$, moderate adherence (41-79\%), and good adherence $(>80 \%)$.

\section{Statistical Analysis}

Data were analysed with the statistical package SPSS version 22, and data are reported, unless stated otherwise, as means and standard deviations (SD). Comparisons of observations obtained before, during and postpartum were done by using either the $\chi^{2}$ test or Fischer's exact test, as appropriate. Likewise, Pearson's or Spearman's correlation analyses were used depending on the data analysed. p values $<0.05$ were considered significant.

\section{Statement of Ethics}

All subjects gave informed consent, and the study was approved by the Research Ethics Committee of the Capital Region of Denmark (H-D-2007-0051).

\section{Results}

\section{Patients}

A total of 130 women (mean age 31.6 years, range 20 42) were included in the present study. Baseline characteristics of the enrolled patients are given in table 1 . The majority of patients were never smokers (71.1\%), and only 2 patients $(2.7 \%)$ were current smokers.

Forty-seven patients (36\%) had previously had an acute exacerbation of asthma requiring treatment with systemic corticosteroid, and 25 patients (19\%) had previously been hospitalized for asthma.

\section{Prescribed Controller Therapy}

Most of the patients were prescribed budesonide $(69 \%)$, whereas the remaining patients were prescribed either fluticasone (15\%) or beclomethasone (BDP; 3\%). The mean pre-pregnancy prescribed daily dose of ICS (BDP equivalent) was $424 \mu \mathrm{g}$ (SD 157), and no significant change in the daily ICS dose was observed towards the
Table 1. Characteristics of the patients $(n=130)$ at the time of enrolment

\begin{tabular}{ll}
\hline Age, years & $31.6 \pm 5.1(20-42)$ \\
Body mass index & $28.2 \pm 7.6(17.6-49.0)$ \\
\hline Duration of asthma, years & $13.7 \pm 9.7(1-40)$ \\
\hline Allergy & $101(78)$ \\
Allergic rhinitis & $90(69)$ \\
\hline Disposition to allergic disease & $98(75)$ \\
Pet(s) at home & $17(13)$ \\
\hline FEV, liter & $2.98 \pm 0.55(1.49-4.09)$ \\
FEV $_{1}, \%$ pred & $92.5 \pm 12.8(64.2-122.1)$ \\
FEV $_{1} /$ FVC & $0.80 \pm 0.07(0.58-0.93)$ \\
\hline FeNO, ppb & $21.5 \pm 11.8(3.2-53.0)$ \\
\hline
\end{tabular}

Values are mean \pm SD (range) or $\mathrm{n}(\%)$.

end of pregnancy (mean daily dose $385 \mu \mathrm{g}$, SD 154, $\mathrm{p}=$ $0.34)$.

\section{Assessment of Asthma Control at Enrolment}

At the time of enrolment, 83 patients (64\%) were classified as having well-controlled asthma, whereas 30 patients (23\%) and 17 patients (13\%), respectively, had partly controlled and uncontrolled asthma. Further characteristics of disease activity at enrolment are given in table 1.

\section{Self-Reported Adherence to ICS}

Sixteen women reported at the first visit that they had not taken their prescribed ICS for at least 6 months, and the adherence analyses are therefore based on the remaining 114 patients.

In general, self-reported adherence was consistent throughout the pregnancy period. Self-reported adherence to ICS was significantly better during pregnancy compared with the pre-pregnancy period ( $\mathrm{p}<0.001)$, as $83(73 \%)$ and 59 (52\%) women, respectively, reported good adherence (fig. 1). However, at the 3 -month postpartum visit, only $50 \%$ of the women reported good adherence.

\section{Adherence to ICS Defined as MPR}

Overall adherence, defined as MPR, was 28\% (SD 25) in the pre-pregnancy period compared with $46 \%$ (SD 31) during pregnancy $(\mathrm{p}<0.0001)$ (fig. 2$)$, and the increase in MPR was most pronounced in the second trimester of pregnancy. However, 27 (24\%) of the patients did not fill prescriptions $(\mathrm{MPR}=0)$ for ICS during the pre-pregnan- 


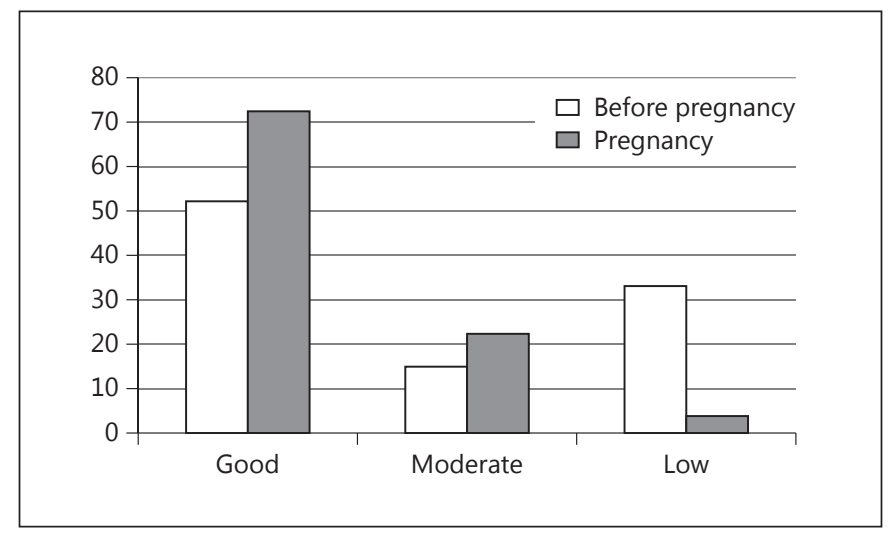

Fig. 1. Self-reported adherence with ICS before and during pregnancy $(\mathrm{n}=114)$.

cy period, whereas 20 (18\%) of these 27 patients did not fill prescriptions for ICS during pregnancy $(\mathrm{MPR}=0)$. For those patients $(n=94)$ who filled at least one prescription for ICS during pregnancy, adherence was 34\% (SD 24 ) in the pre-pregnancy period and $56 \%$ (SD 25) during pregnancy $(\mathrm{p}<0.0001)$. The distribution of the level of adherence in the pre-pregnancy period versus that during pregnancy is given in figures 2 and 3 . Confining the analysis to women with poor adherence with ICS in the prepregnancy period revealed that 56 and 15\%, respectively, had moderate and good adherence during pregnancy. During the 3-month postpartum period, the overall MPR was $32 \%$.

Stratifying the analyses by asthma severity, including the history of previous exacerbations, did not change the findings.

\section{Self-Reported Adherence versus Adherence Assessed as $M P R$}

No significant correlation was found between self-reported adherence and adherence assessed as MPR in the pre-pregnancy period or the postpartum period ( $\mathrm{p}=0.46$ and $\mathrm{p}=0.37$, respectively), whereas a relatively weak but statistically significant correlation was found between self-reported good adherence (73\%) and MPR adherence $(46 \%)$ during pregnancy $(\mathrm{p}=0.004)$.

\section{Changes in Asthma Characteristics during Pregnancy}

Of the 114 women reporting current use of ICS at baseline, 100 patients $(88 \%)$ could be classified as having wellcontrolled asthma at the last visit before delivery (compared to 68 patients at baseline). Furthermore, also com-

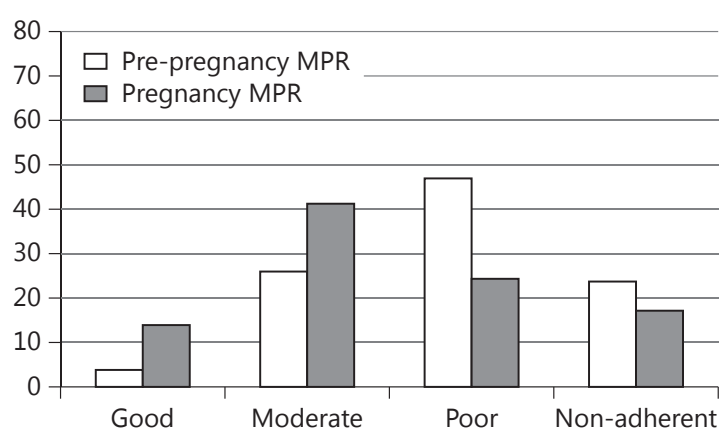

Fig. 2. Actual adherence (i.e. MPR) with ICS before and during pregnancy in 114 women with asthma-prescribed maintenance therapy.

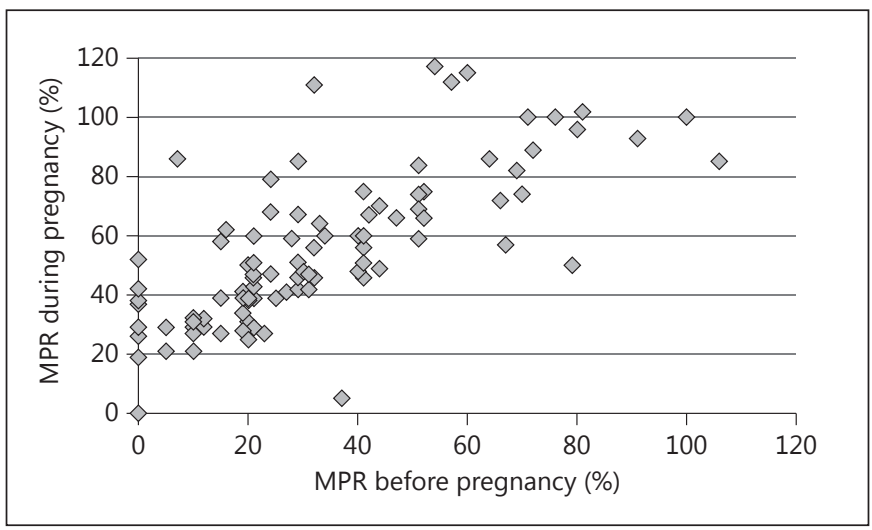

Fig. 3. Adherence to ICS, defined as MPR, during the pre-pregnancy period (270 days; $x$-axis) and pregnancy (270 days; $y$-axis) in 114 women prescribed daily controller therapy for asthma.

pared with baseline, an improvement was observed in FEV1 $(\mathrm{p}<0.05)$ together with a reduction in FeNO $(\mathrm{p}<$ $0.001)$.

\section{Discussion}

This study showed, to our knowledge as the first, that enrolment in an asthma management program, and by that close monitoring of disease activity, during pregnancy is very likely to improve adherence with ICS, as the actual adherence (assessed by MPR) increased from $28 \%$ before pregnancy to $46 \%$ during pregnancy. Further- 
more, when confining the analysis to women who filled at least one prescription for ICS during pregnancy, it revealed an increase in actual adherence from 34 to 56\%, respectively. Although no control group was included in the present study, our findings of a clinically meaningful improvement in adherence caused by the intervention is strongly supported by the accompanying improvement in overall asthma control.

In accordance with previous studies [22], the present study showed that self-reporting, in general, is not a valid measure of actual adherence to ICS, although we observed that it seems to be more accurate during pregnancy than in non-pregnant women. This could be due to the women feeling responsible for more than their own health, and thus reporting more truthfully, or it could be a coincidence.

Previous studies have reported lower adherence to ICS during pregnancy $[13,23]$. In contrast to this, the present study showed a substantial increase in actual adherence during pregnancy. The most likely explanation seem to be the close monitoring of asthma control during pregnancy, as the women were seen at the clinic approximately every four weeks during pregnancy. It has been shown that adherence declines between visits [24] and in general is higher after enrolment in a study [25]. Long intervals between asthma-related physician visits before pregnancy may be associated with low adherence, although the observed adherence rate in the pre-pregnancy period is similar to observations reported from studies of nonpregnant patients with asthma [5].

There are several limitations to our study. Firstly, we base our rates of ICS adherence on filled prescriptions, without knowing if the patients actually used their inhalers, and might thus overestimate adherence. Filling a prescription is only the first step towards good adherence, as the patient might use the medication less than prescribed, or even fail to use correct inhaler technique, thus not getting the full effect [26]. Studies have shown level of ICS adherence to be dependent on the method of measuring $[22,27]$, with a general tendency to overestimate adherence, especially in self-reporting, canister weighing and physician evaluation. Secondly, we defined the adherence period during pregnancy as 9 months before delivering the baby. This poses a possible error, as most women do not know they are pregnant before experiencing a missed period, and thus may follow their usual ICS intake for several weeks after our calculated index date. One way of addressing this issue might be to obtain information from the women about the day they had a positive pregnancy test, and use this as the index date. Finally, as no control group was included in the present study, the improvement in adherence with ICS might be due to the pregnancy itself and not the close monitoring, but this would be in contrast to previous observations $[13,23]$ and the reported tendency amongst general practitioners to decrease, or even discontinue, treatment with ICS in pregnancy [14]. Furthermore, as all women referred to Hvidovre Hospital for giving birth are invited to participate in the MAP program, and by that are offered frequent visits to the outpatient clinic if they have asthma, including a control group, presumably with only visits in early pregnancy and postpartum, would have meant less than standard care for women in the control group, also compared to standard care for our non-pregnant patients with asthma. In our view, this poses an ethical dilemma, and we therefore decided not to include a control group in the present study.

The cut-off value for adherence has been much debated. Apter et al. [3] used a value of $70 \%$ to separate good adherence from poor adherence. Others have used 75 and $50 \%$ as the cut-off value. However, $80 \%$ has often been used, and a study by Lasmar et al. [28] have shown this to be the threshold between controlled and uncontrolled asthma. In contrast to this, Schroeder et al. [29] argue that the common cut-off value of $80 \%$ often is meaningless, not based on sufficient evidence, and that it would be better to use a continuous measure of adherence instead of cut-off values. Attempting this by dividing adherence into more than one group, Williams et al. [30] used 0-25, 26-50, 51-75 and 76-100\%.

Our results reflect on the fact that adherence to ICS is a major problem in achieving optimal asthma control. The low mean adherence before pregnancy, as well as the high number of non-adherent patients, shows us that there is room for improvement. Even with the increase we saw during pregnancy, the mean adherence did not reach $50 \%$.

It is well documented that maternal asthma, probably primarily not well-controlled asthma, increases the risk for nearly all adverse obstetric outcomes [31-33]. In order to prevent these, it is important to maintain good asthma control during pregnancy. A possible way to achieve this could be through closely scheduled visits [10], educating the patients on potential risks and benefits of ICS during pregnancy, and adverse outcomes associated with poor asthma control [34]. Objective measures may have a prognostic value, as Powell et al. [35] found a reduction in exacerbations when adjusting ICS according to FeNO levels in monthly visits, and Schatz et al. [36] found lower pulmonary function to be associated with poor outcomes. 
In conclusion, our study showed that close monitoring of asthma during pregnancy is very likely to improve adherence with ICS, although the actual adherence remained disturbingly low. Furthermore, we found that self-reported adherence is not a valid measure of actual adherence before pregnancy, thus most likely also in nonpregnant patients with asthma, whereas self-reported adherence correlated with actual adherence during pregnancy. To improve maternal asthma control, and thus reduce the frequency of adverse obstetric outcomes, it is important to increase the level of ICS adherence. The challenge now is to find strategies to ensure optimal ther- apeutic alliances, in hope that having the patient as an active partner in the treatment will improve the level of adherence.

\section{Acknowledgement}

The authors wish to thank all women participating in the present study.

\section{Financial Disclosure and Conflicts of Interest}

The authors declare that they have no competing interests.

\section{References}

1 Ulrik CS, Claudius BK, Tamm M, Harving H, Siersted HC, Backer V, Hellquist B, Dahl R, Hogholm A, Johnk IK: Effect of asthma compliance enhancement training on asthma control in patients on combination therapy with salmeterol/fluticasone propionate: a randomised controlled trial. Clin Respir J 2009;3:161-168.

2 Cochrane MG, Bala MV, Downs KE, Mauskopf J, Ben-Joseph RH: Inhaled corticosteroids for asthma therapy: patient compliance, devices, and inhalation technique. Chest 2000;117:542-550.

-3 Apter AJ, Reisine ST, Affleck G, Barrows E, ZuWallack RL: Adherence with twice-daily dosing of inhaled steroids. Socioeconomic and health-belief differences. Am J Respir Crit Care Med 1998;157:1810-1817.

4 Ahmedani BK, Peterson EL, Wells KE, Rand CS, Williams LK: Asthma medication adherence: the role of God and other health locus of control factors. Ann Allergy Asthma Immunol 2013;110:75-79 e72.

5 Baarnes CB, Ulrik CS: Asthma and adherence to inhaled corticosteroids: current status and future perspectives. Respir Care 2015;60:455468.

-6 Ulrik CS, Backer V, Soes-Petersen U, Lange P, Harving H, Plaschke PP: The patient's perspective: adherence or non-adherence to asthma controller therapy? J Asthma 2006;43: 701-704.

7 Lemmens KM, Nieboer AP, Huijsman R: A systematic review of integrated use of diseasemanagement interventions in asthma and COPD. Respir Med 2009;103:670-691.

8 Moullec G, Gour-Provencal G, Bacon SL, Campbell TS, Lavoie KL: Efficacy of interventions to improve adherence to inhaled corticosteroids in adult asthmatics: impact of using components of the chronic care model. Respir Med 2012;106:1211-1225.
9 Kwon HL, Triche EW, Belanger K, Bracken MB: The epidemiology of asthma during pregnancy: prevalence, diagnosis, and symptoms. Immunol Allergy Clin North Am 2006; 26:29-62.

10 Stenius-Aarniala B, Piirila P, Teramo K: Asthma and pregnancy: a prospective study of 198 pregnancies. Thorax 1988;43:12-18.

11 Murphy VE, Namazy JA, Powell H, Schatz M, Chambers C, Attia J, Gibson PG: A metaanalysis of adverse perinatal outcomes in women with asthma. BJOG 2011;118:13141323.

12 Enriquez R, Griffin MR, Carroll KN, Wu P, Cooper WO, Gebretsadik T, Dupont WD, Mitchel EF, Hartert TV: Effect of maternal asthma and asthma control on pregnancy and perinatal outcomes. J Allergy Clin Immunol 2007;120:625-630.

13 Chambers K: Asthma education and outcomes for women of childbearing age. Case Manager 2003;14:58-61.

14 Lim AS, Stewart K, Abramson MJ, George J: Management of asthma in pregnant women by general practitioners: a cross sectional survey. BMC Fam Pract 2011;12:121.

15 National Heart L, Blood I, National Asthma E, Prevention Program A, Pregnancy Working Group: NAEPP expert panel report. Managing asthma during pregnancy: recommendations for pharmacologic treatment-2004 update. J Allergy Clin Immunol 2005;115: 34-46.

16 Gregersen TL, Ulrik CS: Safety of bronchodilators and corticosteroids for asthma during pregnancy: what we know and what we need to do better. J Asthma Allergy 2013;6:117125.

17 Bateman ED, Hurd SS, Barnes PJ, Bousquet J, Drazen JM, FitzGerald M, Gibson P, Ohta K, O'Byrne P, Pedersen SE, et al: Global strategy for asthma management and prevention: GINA executive summary. Eur Respir J 2008; 31:143-178.
18 Miller MR, Hankinson J, Brusasco V, Burgos F, Casaburi R, Coates A, Crapo R, Enright P, van der Grinten CP, Gustafsson P, et al: Standardisation of spirometry. Eur Respir J 2005; 26:319-338.

19 Quanjer PH, Tammeling GJ, Cotes JE, Pedersen OF, Peslin R, Yernault JC: Lung volumes and forced ventilatory flows. Report Working Party Standardization of Lung Function Tests, European Community for Steel and Coal. Official Statement of the European Respiratory Society. Eur Respir J Suppl 1993;16: 5-40.

20 American Thoracic S, European Respiratory S: ATS/ERS recommendations for standardized procedures for the online and offline measurement of exhaled lower respiratory nitric oxide and nasal nitric oxide, 2005. Am J Respir Crit Care Med 2005;171:912-930.

21 Vollmer WM, Feldstein A, Smith DH, Dubanoski JP, Waterbury A, Schneider JL, Clark SA, Rand C: Use of health information technology to improve medication adherence. Am J Manag Care 2011;17:SP79-SP87.

22 Patel M, Perrin K, Pritchard A, Williams M, Wijesinghe M, Weatherall M, Beasley R: Accuracy of patient self-report as a measure of inhaled asthma medication use. Respirology 2013; 18:546-552.

23 Enriquez R, Wu P, Griffin MR, Gebretsadik T, Shintani A, Mitchel E, Carroll KN, Hartert TV: Cessation of asthma medication in early pregnancy. Am J Obstet Gynecol 2006;195: 149-153.

24 Cramer JA, Scheyer RD, Mattson RH: Compliance declines between clinic visits. Arch Int Med 1990;150:1509-1510.

25 Rand CS, Nides M, Cowles MK, Wise RA, Connett J: Long-term metered-dose inhaler adherence in a clinical trial. The Lung Health Study Research Group. Am J Respir Crit Care Med 1995;152:580-588. 
26 Molimard M: How to achieve good compliance and adherence with inhalation therapy. Curr Med Res Opin 2005;21(suppl 4):S33S37.

-27 Braunstein GL, Trinquet G, Harper AE: Compliance with nedocromil sodium and a nedocromil sodium/salbutamol combination. Compliance Working Group. European Respir J 1996;9:893-898.

28 Lasmar L, Camargos P, Champs NS, Fonseca MT, Fontes MJ, Ibiapina C, Alvim C, Moura JA: Adherence rate to inhaled corticosteroids and their impact on asthma control. Allergy 2009;64:784-789.

29 Schroeder K, Fahey T, Ebrahim S, Peters TJ: Adherence to long-term therapies: recent WHO report provides some answers but poses even more questions. J Clin Epidemiol 2004;57:2-3.
30 Williams LK, Peterson EL, Wells K, Ahmedani BK, Kumar R, Burchard EG, Chowdhry VK, Favro D, Lanfear DE, Pladevall M: Quantifying the proportion of severe asthma exacerbations attributable to inhaled corticosteroid nonadherence. J Allergy Clin Immunol 2011;128:1185-1191.e1182.

31 Namazy JA, Schatz M: Treatment of asthma during pregnancy and perinatal outcomes. Curr Opin Allergy Clin Immunol 2005;5: 229-233.

32 Piette V, Demoly P: Asthma and pregnancy. Review of the current literature and management according to the GINA 2006-2007 guidelines (in French). Rev Mal Respir 2009; 26:359-379; quiz 478, 482.
33 Mendola P, Laughon SK, Mannisto TI, Leishear K, Reddy UM, Chen Z, Zhang J: Obstetric complications among US women with asthma. Am J Obstet Gynecol 2013;208:127 e121-128.

34 Dombrowski MP, Schatz M: Asthma in pregnancy. Clin Obstet Gynecol 2010;53:301-310.

35 Powell H, Murphy VE, Taylor DR, Hensley MJ, McCaffery K, Giles W, Clifton VL, Gibson PG: Management of asthma in pregnancy guided by measurement of fraction of exhaled nitric oxide: a double-blind, randomised controlled trial. Lancet 2011;378:983-990.

36 Schatz M, Dombrowski MP, Wise R, Momirova V, Landon M, Mabie W, Newman RB, Rouse DJ, Lindheimer M, Miodovnik M, et al: Spirometry is related to perinatal outcomes in pregnant women with asthma. Am J Obstet Gynecol 2006;194:120-126. 